\title{
The Perceived Meaning of Verbal and Non-Verbal Expressions in Chitato "Life is Never Flat" Advertisement
}

\author{
Clarista Jofeda Gunawan \\ English Department, Faculty of Languages and Literature, Petra Christian University \\ Siwalankerto 8, Surabaya 60236, East Java, INDONESIA \\ E-mail: claristajofeda18@gmail.com
}

\begin{abstract}
This thesis mainly deals with verbal and non-verbal expression to uncover hidden messages in the video commercial of Chitato themed 'Life is Never Flat', starred by Agnes Monica, taken from Youtube Channel. The writer focuses on the lyrics, the actress, as well as the colors involved in the scenes, and relates them to the theories of Chandler on verbal and non-verbal expression in order to find perceived meanings. In the analysis, the writer uses the theories to find out some hidden messages got by respondents after they watch the video commercial. In the analysis, the writer used descriptive qualitative method as her approach to describe meanings in the advertisement as her research. The respondents participated in the interview in order to find the hidden messages are ten people, consisting of old and young people. Based on the analysis, the writer has found out that the commercial of Chitato's delivered denotation and connotation through its lyrics, the actress, and the colors. In conclusion, based on the result, the writer has found that Chitato's advertisement invites audiences to feel great and enjoy their day by spending time with Chitato.
\end{abstract}

Keywords: perceived meanings, advertisement, descriptive qualitative

\section{INTRODUCTION}

Advertisement is a paid form of non-personal presentation in business firms as the promotion of goods, services, and ideas created by identified sponsors. From the definition, it is defined that an advertisement is used to introduce a product and create a direct persuasive for viewers as its marketing targets. From this statement, it means that advertisement is able to introduce people by delivering meanings involved it so that it will persuade consumers to buy the product because it attracts them to either watch or read, and understand what they want and need through its detailed information, such as prices, packaging, as well as the use of the product. Based on the explanation, it means that an advertisement has become a vital role to introduce a product sold to targets. A message in an advertisement has a role to tell a simple story to convey information and uses basic emotional appeals, symbolic languages, and images related to the senses. In this communication tool, Kotler (2006, pp. 404) described how communication works, which are encoding, decoding, response, and feedbacks. In this process, a sender and a receiver become parties, and messages and media as major communication tools. When senders transmit messages, they need efficient media to encode their messages to audiences so they get feedbacks or responses from the receivers. To gain the feedbacks, it means that media become a vital role to provide messages sent to receivers, which were motion pictures called video advertisements, booklets, leaflets, and display signs. From those media, as the sources of messages, receivers will decode detailed messages well and see what feedbacks they will give to senders. In sending a sign through promoting and introducing, according to Kotler (2006, pp. 341 - 356), there are some specific cores such as symbols, taglines, and colors as messages delivered in order to describe a product in an advertisement.

\section{METHOD}

\section{Approach of the Study}

To collect the data, the writer will use descriptive qualitative by Mukhtar because her research is about identifying the signs of the advertisement through different perspectives from people. In this research, she needs to explain about the methods related to the theories, approach to the study, and data collection used to support the methods. The approach used in this study is descriptive qualitative which is defined as a method used to analyze data from pictures, description, explanation, and information. During the interview, the targets of interview have their own 
perceptions about an object researched. In doing this research, a writer must know why the object is worthy to be analyzed and how many people will be interviewed. Besides that, the writer also have to know that targets of an interview can have different perceptions about the object analyzed so the writer cannot argue with them. In analyzing data, the writer needs to complete the data first by either interviewing or discussing with her targets as respondents. As what Mukhtar says, that an interview and discussing should be done elaborately, which means that the writer must encourage each respondent to be critical in giving their own perspectives during the interview and discussing.

\section{Method of Data Collection}

The source of data is a video advertisement of Chitato with the tagline 'Life is Never Flat', starred by Agnes Monica as well as her dancers (2009). In the first scene, the video portrayed two boys not getting their tickets for an event then they looked hopeless and had no ideas to do. One of them ate a slice of Chitato and suddenly another man took one slice as well. After they ate one slice, they directly dance and looked happy as if they were entertaining themselves. Another scene portrayed Agnes Monica dancing with her friends then she starred the two men in the previous scene doing dance walking and shared Chitato to Agnes Monica, and they all are doing dance walking to the streets with holding Chitato with various flavors. From this video, the writer will see the comparison between both young and old people perception. In this research, she has chosen young and old people because based on society, young and old people recently always have different perception towards something.

Before the interview, she needs to prepare the video and the lyrics of the song of the advertisement. During the interview, the writer will start with a daily conversation in order to bring a good atmosphere, then she will show the video advertisement to the targets and let them see the meaning behind the video specifically. When the interview begins, the writer shows her target the Chitato's video and ask the target to memorize the story of the advertisement. The video will be played twice or more in order to help them memorize the story line of the advertisement. After they watch the video, the writer will ask them some questions related to the research in order to know how people understand about messages delivered through the videos. The questions asked to the targets are from verbal expression and visual expression of the advertisement. Moreover, the writer also needs to record the whole interview in order to transcribe it. This will help the writer to remind all answers of the targets during the interview and to complete the data. In finding the data, the writer needs to decide what object she is going to ask to her respondents.

\section{FINDINGS AND DISCUSSION}

\section{The Summary of Discussions of Perceived meanings' Analysis in Verbal Expression (Old and Young People)}

In the first lyric, 'Here we go,....', the lyric emphasizes that Chitato is more delicious than any other snacks so that it is the reason why people have to try Chitato. Old people, as respondents have concluded that the lyric asks everyone to enjoy every moment they have, either with friends or not. From the respondent's answers, the respondents might remember that a boy in the first scene ate Chitato in front of his friend who was sad. For young people, the respondents think that the caption persuades people to be energetic to do all things. From their opinion, they might had focused on the words 'Come on come on', which sounded like motivating people not to give up and stay strong. From the young people's perspectives, young people have implied that Chitato makes them feel energetic because the snack can build a spirit to whomever they are with so they will never be tired and bored.

In the second caption, 'Life is never flat', old people, as respondents have revealed that the caption reminds everyone about life. As the respondents have said in the table, they conclude that the caption 'Life is never flat' emphasizes that people will always get problems and solve them as long as they live. From the opinion, the respondent actually thought that the caption reminded them that life brings new challenges every day and people will pass through them in order to get their good feelings back. Moreover, the respondents might be reminded by the caption about their struggles and experiences they have done in their life. Meanwhile, young people have said that life will never be 
bored as long as you have Chitato wherever you are. From the answer, those respondents probably had seen that Chitato was able to build a friendship and a good moment people had in the scenes. In the scenes when the rapper said 'Life is never flat', the scenes always showed the moment when the teenagers were sharing Chitato to others so it invited the respondents to assume that this caption emphasized that life will never be bored because people will have a good moment with friends since they have Chitato.

In the third caption, 'Don't be mad, feel so flat,.....', all old people respondents think that the caption advises people not to be upset and overthink problems they have. From the answer, the respondent has revealed that opinion because they saw the previous caption, 'Life is never flat, which was emphasized that people will always get their own problems every day and those can ruin their feelings. Meanwhile, young people here have emphasized that everyone had better eat Chitato not only when they are bored, but also when they have a good feeling because it will make people feel better and enjoy their day more.

In the fourth caption, 'You won't gonna be flat, are you ready to go?', old people comprehended that the caption was more like proving someone because in that lyric, Agnes Monica said 'Are you ready to go?', which sounded like inviting the respondents to assume that she wanted to challenge everyone to taste Chatato's flavors. From this caption, old people, as the respondents have a perceived meaning that this caption looks like giving a challenge to everyone who doubts about the flavors. Meanwhile, young respondents tend to see that this caption invited people to try Chitato and enjoy the moment they had with others. Those respondents has seen that meaning because they might had seen the words 'are you ready to go?' as the invitation for others to get a good moment with Chitato.

In the fifth caption, 'You and Chitato are...', old people has found the perceived meaning that Chitato changes people's day better and the moment will be enjoyable as long as they have Chitato. The respondents might think that the word 'the perfect match' means a perfect friend. Meanwhile, all young respondents have concluded that Chitato will complete people's life well when once they eat it. From the respondent's answer, they might have thought that the words 'perfect match' means that people had better bring Chitato wherever they go to share it with others, and that words show people that their most perfect match is actually Chitato because it can entertain them only by one bite so that means nobody can entertain you except Chitato.

\section{The Summary of Discussions of Perceived meanings' Analysis in Visual Expression (Old and Young People)}

In the first caption, Agnes Monica biting Chitato, old people, as respondents have seen that Chitato's advertisement is starred by Agnes Monica because her characters are nice, which means that she is a young actress, smart, and very talented so she is able to express herself perfectly in the advertisement so it makes Chitato becomes familiar to people. For old people, Agnes has been chosen as the icon because she is able to motivate teenagers in her role as a young actress. Meanwhile, young people have assumed that Agnes shows people that whoever eats Chitato, they will have characters like Agnes Monica's, which are being energetic, motivating, and inspiring.

The second picture shows bright colors which reveal that colors in the advertisement tells people's feelings, such as happiness, sadness, and anxiety. Old people revealed that those feelings are related to the tagline of the advertisement, 'Life is never flat' because there are some feelings that people have in their minds before and after eating Chitato. From this perceive meaning, it is implied that Chitato is able to control people's mind. Meanwhile, young respondents see that the facial expression of Agnes Monica and the meaning of the colors persuade people to eat Chitato because it builds a good atmosphere to everyone and it is a guarantee that Chitato will give you spirit to do all things. From their perceived meaning, it is meant that the colors in Chitato's advertisement has shown that Chitato will bring a good mood to everyone in every situation, and it can bring people's good mood back although they are bored.

In the third caption, where Agnes and her friends dancing with other teenagers with holding Chitato, old people, as respondents has seen that dancing with holding Chitato is to show others that they always have great moments after they eat Chitato. The respondents probably have seen that people in the video looked so enjoying their togetherness while they were holding Chitato. Old people have got the pereived meaning that Chitato is able to complete people's moment everywhere. 
Meanwhile, young respondents assumed that Agnes and friends wanted to show how much energy they got after trying Chitato. The respondent had seen that they looked like dancing with much energy and they did not even look tired at all so that scene invited the respondent to assume that the energy came from Chitato. In general, this scene invited people to have the same experience like theirs because it was so enjoyable.

In the fourth picture, when a boy was biting the chip in front of people and holding Chitato's packaging, old people conclude that the scene tells everyone that they will not be sad as long as they have Chitato and share it to others. Their perceived meaning was supported by the scene, when people directly danced as if they were happy and satisfied. Meanwhile, young people have got the perceived meaning that the boy encouraged people to have their spirit so they would be so energetic and anthusiastic in doing all stuffs. Their perceived meaning was shown by the way he bit the chip and showed his enthusiastic expression. Moreover, the perceived meaning was also supported by his face when biting Chitato. In that scene, he looked enjoying every bite of Chitato.

In the fifth picture, dancing in all scenes, old people, as respondents, revealed that all the dance depicted young people's spirit as long as they are young and have ever tried Chitato. The respondents saw that people who were dancing in the whole scenes were only young people and they all looked so energic so they all invited the respondents to think that the dance was to prove the spirit. Besides, the respondents had seen that no one was sad in the scene and they all look enjoyable when they were dancing so that moment invited the respondent to think that they all get their happiness by Chitato. Meanwhile, young respondents had seen that the dance was to prove that people had a good inspiration by eating Chitato. Based on the video, the respondents had seen that whoever ate Chitato, they would be creative in improving their ability. In that scene, a dancing walk is a proof of their creativity coming from Chitato. For that reason, the respondent implied that Chitato inspires others.

In the last picture, various hair styles, old poeple assumed that the hair styles depicted young people's style nowadays. They also assumed that the snack was special for young people so the hair styles also emphasized that people involved were young people. Besides, the respondents also revealed that the hair styles actually depict the various flavors of Chitato. The perecived meaning was whoever tastes the flavors, they will never be bored, and that was also shown by the fashionable and unique hair styles which were not boring so the hair styles depicted chitato's flavors. Meanwhile, young respondents have implied that the hairstyles in the commerial video showed that they could not be flat as long as they had Chitato because they would enjoy its delicious flavors when they ate it. From this answer, the respondents saw that the hairs styles were unique, same as the unique of Chitato's flavors. For that reason, the respondents had seen that the various hair styles in the advertisment were presenting the various flavors of Chitato. Besides, the hair styles described the incredible flavors of Chitato.

\section{CONCLUSION}

This research deals with perceived meanings coming from the advertisement of Chitato 'Life is never flat' to audience's mind. The analysis is to reveal the perceived meanings of the advertisement showed by verbal which is from the lyrics and visual expression which is from the actors, actresses, as well as the colors in the scenes. The source of the data is a commercial video starred by Agnes Monica and her dancers, taken from Youtube channel.

In this analysis, the writer also used descriptive qualitative method based on Mukhtar's book titled 'Metode Praktis Penelitian Deskriptif Kualitatif' (2013), which emphasizes the approach of descriptive qualitative research in order to find out her research. The method has helped the writer to find the answers by interview. To find the data, the writer chose ten respondents consisted of five old people and five young people. As respondents, they have revealed their own perceptions about the messages in the video commercial after they watched it. The result of the research has revealed the differences between young and old people opinions about the Chitato's advertisements. The perceived meaning of verbal expression, shown by the texts of Chitato's song, proved that old people comprehend that everyone will feel good and relax if they only taste Chitato's flavors because its flavors are various and delicious so it brings a good feeling to everyone. Meanwhile, young people comprehend that Chitato is able to motivate everyone who feels bored or hopeless by only its flavors. Young people mention that Chitato has reminded them to never stop making ideas to make their life perfect. In perceived meaning of the non-verbal expression, old people reveal that Chitato is 
memorable because it has unique flavors. For young people, Chitato's flavors give energy and spirit to everyone so it builds a good atmosphere. In visual expression, old people has seen the perceived meanings that Chitato is memorable and it is sold for young people only, and its flavors depict the spirit of young people. Meanwhile, the perceived meanings in verbal expression got from young people was whoever eats Chitato, they will feel energetic and motivated to do all stuffs. In visual expression, young people has seen that Chitato builds creativity for whoever eats it and builds solidity among people.

\section{REFERENCES}

Barthes, R. (1994). The Semiotics Challenge. California : Basil Blackwell.

Chandler, D. (2007). Semiotics The Basics 2nd edition. London: Routledge.

Creative, (Is). (2016). 12 Best Indonesian Brand Slogans. Retrivied from http://blog.iscreativeworks.com/idealist/12-best-indonesian-brand-slogans

Kotler, P. (2006). Principles of Marketing 11th edition. New Jersey: Pearson Education.

Kress, G. and Van Leeuwen, T. (2002). Colour as a semiotic mode: notes for a grammar of colour. http://journals.sagepub.com/doi/abs/10.1177/147035720200100306

Mussari, M. (2002). Would Have Made a Bad Fauve. Retrivied from http://journal.mediaculture.org.au/0207/eco.php

M.Pd, Mukhtar. (2013). Metode Praktis Penelitian Deskriptif Kualitatif. Jakarta: Ciputat.

Shanthana, J. (2018). Denotative and Connotative Meanings in Wonderfilled Advertisement of Oreo. (TA No.-/ING/2018). Unpublished Undergraduate Thesis, Petra Christian University, Surabaya. Surabaya.

Susanti's, O. (2007). Mengungkap Makna Iklan Rexona 'Cheerleader Pria' di Televisi. (TA No. 10010167/KOM/2007). Unpublished Undergraduate Thesis, Petra Christian University, Surabaya.

Youtube. (2009). TVC Agnes Monica Chitato LIfe Is Never Flat Potato Chips Dipra Communications. Retrivied from https://youtu.be/rHMWoa2inus 